\title{
Bladder Cancer and Cancer Stem Cells: Basic Science and Implications for Therapy
}

\author{
Richard T. Bryan \\ The School of Cancer Sciences and The Department of Public Health, Epidemiology \\ and Biostatistics, University of Birmingham, Birmingham, U.K. \\ E-mail: r.t.bryan@bham.ac.uk
}

Received January 13, 2011; Revised May 18, 2011, Accepted May 25, 2011; Published June 9, 2011

Bladder cancer is the fifth most common cancer in Western society, with the global burden predicted to increase significantly in the foreseeable future. Over $90 \%$ of these bladder cancers are transitional cell carcinomas of urothelial origin (urothelial carcinomas or UCs) and at presentation, over $70 \%$ will be non-muscle-invasive or stage $\mathrm{Ta} / \mathrm{T} 1$ tumours, with the remainder being muscle-invasive or stages T2-4. Bladder UC is a highly heterogeneous disease: for the $50-55 \%$ of bladder cancer patients presenting with Ta tumours, recurrence is the main issue, but for the $20-25 \%$ of patients presenting with T1 tumours, progression is the main issue. Progression to, or presentation with, muscleinvasive disease represents the critical step for patients, necessitating more aggressive therapies and carrying significantly worse survival rates. We therefore urgently require detailed molecular insights into the pathogenesis of muscle-invasive bladder cancer so that the disease can be more adequately and appropriately treated at presentation, so that progression from stages $\mathrm{Ta} / \mathrm{T} 1$ can be abrogated, and so that the risk of recurrence following treatment can be minimised. The recently identified bladder cancer stem cells are considered to be mediators of resistance to current therapies and therefore represent strong candidate biological targets. The aim of this review is to discuss the background and basic science of such cells, and the implications for current and future therapies.

KEYWORDS: bladder cancer, stem cells, cancer stem cells

\section{INTRODUCTION}

Bladder cancer is the fifth most common cancer in Western society, with a global incidence of over 356,000 new cases per year and a prevalence estimated at 2.7 milion cases[1,2]. The global burden of bladder cancer is predicted to increase significantly in the foreseeable future as a result of population aging and the increasing world population, together with the progression of the tobacco epidemic and increasing exposure to occupational carcinogens in developing countries[2]. In the U.K., we observe 10,200 new cases and 5,000 deaths per year[3]. Over 90\% of these bladder cancers are transitional cell carcinomas (TCC) of urothelial origin (urothelial carcinomas or UCs) and at presentation, over 70\% will be non-muscle-invasive or stage $\mathrm{Ta} / \mathrm{T} 1$ tumours, with the remainder being muscle-invasive or stages $\mathrm{T} 2$ $4[1,4,5,6]$. 
Bladder UC is a highly heterogeneous disease[7]: for the $50-55 \%$ of patients presenting with Ta tumours, recurrence is the main issue, occurring in up to $80 \%$ of cases[1,4], whereas for the $20-25 \%$ of patients presenting with $\mathrm{T} 1$ tumours, progression is the main concern, occurring in $45 \%$ of cases[1,4]. However, it is progression to, or presentation with, muscle-invasive disease that represents the critical step in the disease course, necessitating more aggressive therapies (including radical surgery, chemotherapy, or radiotherapy), and carrying a 5-year survival rate of only $27-50 \%$ (compared with over $73 \%$ for Ta/T1 disease) and a median survival of only 7-20-months for patients with unresectable metastatic disease[4,8,9]. However, despite treatment success in many patients, these aggressive therapies still represent crude approaches that carry significant morbidity and mortality themselves[6,10,11,12,13,14].

We therefore require more detailed biological and molecular insights into the pathogenesis of muscleinvasive bladder cancer so that the disease can be more adequately and appropriately treated at presentation, so that progression from stages Ta/T1 can be abrogated, and so that the risk of recurrence and death following treatment can be minimised. To achieve this, we must consider the genetic and epigenetic alterations involved in tumour development, and the molecular pathways associated with these alterations, which subsequently drive these tumours towards epithelial-to-mesenchymal transition (EMT) and ultimately towards a "cancer stem cell" phenotype[15,16]. In this regard, stem cell and cancer stem cell pathways therefore represent important candidate biological targets[13,17,18,19]: the relative insensitivity of such cells to therapy[20] (even the latest "targeted" therapies) and their considered ability to metastasize highlight the need for us to attack their specific vulnerabilities in order to deliver durably effective cancer treatments[7,21]. The former areas of research have been reviewed in detail elsewhere by significant workers in the field and our understanding has developed greatly[9,16,20,21,22,23,24,25], and several reviews cover the general cancer stem cell topic in detail[13,19,20,26,27]. Here, I shall attempt to discuss the key cancer stem cell concepts, background, and basic science that are of relevance for bladder $\mathrm{UC}$, and the implications for current and future therapies.

\section{STEM CELLS AND CANCER STEM CELLS}

Whilst solid tumours can be reduced in size or totally removed, disease progression or relapse often occurs[13,19]. These phenomena may be explained by the persistence of residual tumour-initiating cells (TICs) and tumour-maintaining cells, and such cells have been reported in a variety of human malignancies (breast, brain, prostate, lung, pancreas, etc.) since their original identification in leukaemia[13,28,29]. It is proposed that these cells are the "original cells" of a tumour, responsible for tumorigenesis, tumour differentiation, tumour maintenance, tumour spread, and tumour relapse[13,17,19,27,30]. These properties are analogous to a stem cell, the original cell of an organ and responsible for organogenesis and organ maintenance, and so these cells have been termed "cancer stem cells" (CSCs) $[13,17,19,27]$. CSCs are thus a subset of tumour cells that have the ability to self-renew and to generate all of the heterogeneous cells that comprise a tumour[21,29]. It has been suggested that it is the CSCs that need to be eradicated to provide long-term disease-free survival; yet, as mentioned above, it appears that CSCs are more resistant to current therapies[18,21,27,31].

Self-renewal and differentiation capacity are the hallmark traits of stem cells, mirrored by the high proliferative capacity and phenotypic plasticity of tumour cells[13,17]. These parallel properties have led to the hypotheses that:

1. Cancer cell populations may include CSCs: rare cells, with indefinite potential for self-renewal, and driving tumorigenesis[17,19].

2. Tumours may originate from the transformation of normal stem cells, since stem cells have a life span long enough to accumulate the number of mutations that cause malignant transformation[13,19,31,32].

3. Similar signalling pathways may regulate stem cells and cancer cells $[13,17,19]$. 
The origin of CSCs has not been established, especially at which level of cell lineage a cell may be turned into a CSC by one or more mutations[13]. These origins are likely to vary from one tumour type to another[20]. However, I and others propose that the development of CSCs in bladder UC most likely occurs following EMT[16,33] as has been demonstrated in other epithelial malignancies[15]. In the laboratory, the occurrence of CSCs varies according to tumour type and to the specific experimental systems used, and controversy continues regarding the frequency and even the existence of CSCs[18,29]. However, the evidence does favour the existence of subpopulations of cells in some solid tumours that satisfy the functional criteria of CSCs[26,29]. It has also been suggested that a dynamic equilibrium may exist between CSCs and non-CSCs within tumours, with non-CSCs from different tumours possessing differing susceptibilities to becoming CSCs[29]; optimal therapeutic regimes would therefore need to incorporate agents to target both CSCs and non-CSCs[29].

A better understanding of benign bladder stem cell biology may enable us to identify and characterise bladder CSCs[13,19], but, to date, definitive cell surface immunophenotypes have not been defined for most stem cells. A study by Signoretti et al. suggested the notion that umbrella and basal/intermediate cells were either entirely independent lineages capable of self-renewal or were maintained by a common p63-negative progenitor cell[34]. Therefore, until recently, bladder stem cells had not been clearly identified[13,27,32,35]. However, it was believed that there was a proliferative basal cell layer that contained a pool of stem cells responsible for replenishing the more differentiated umbrella cells that form the superficial layer of the normal urothelium[21,36], and this hypothesis was supported by the existence of monoclonal patches covering the bladder[36]. Thangappan and Kurzrock investigated this in more detail and demonstrated the existence of three distinct cell types in the normal urothelium: basal cells with stem cell qualities; an intermediate population of committed progenitors with limited proliferative capacity responsible for amplification of each stem-cell division and akin to the "transit amplifying" cells of the skin, residing in the basal and intermediate compartments of the urothelium; and the terminally differentiated superficial umbrella cells[36].

\section{BLADDER STEM CELLS AND CANCER STEM CELLS}

As discussed above, stem cells are able to reproduce themselves, have a high capacity for cell division and a long life, and can produce at least one type of highly differentiated descendent[32,35]. Stem cells are also slower-cycling cells that retain nucleic acid labels for longer periods of time, in contrast to more rapidly cycling cells that incorporate such labels faster, mature, and then die[32]. Thus, they have also been termed "label-retaining cells" or LRCs[32,37]. The urothelial stem cell "niche" is the stem cell's anatomical and functional microenvironment, protecting it from differentiation, loss of self-renewal capacity, and apoptosis[13] and, prior to the studies of Thangappan and Kurzrock[36], this had already been presumed to be along the basement membrane[18,32,38]. LRCs had been localised to this basal layer, with these cells being associated with poorly differentiated UCs and demonstrating stem cell-like properties[7,32]. These cells also shared cytokeratin and cell surface marker expression profiles with bladder TICs[18]. Furthermore, cells derived from this layer were highly tumorigenic cells (HTCs) with enhanced growth potential and multipotency[38]. Such cells also show regulation of Wnt pathway components in a pattern expected to stimulate Wnt signalling activity, as suggested by up-regulation of some Wnt targets (e.g., myc) and accumulation of the Wnt pathway effector, $\beta$-catenin[38]. The Wnt signalling pathway regulates stem cell maintenance and differentiation in a variety of tissues[13,19,39], and it was therefore proposed that during tumorigenesis, some UCs have a basal population at the tumourstroma interface that resemble benign urothelial stem cells and that may represent CSCs[38]. This population differentiates as it moves away from this basal compartment and loses tumour-forming potential upon differentiation[38]. Stem-like properties may be subsequently reproduced at the invasive front, possibly within another niche at this tumour-stroma interface[13,38].

For some time, however, CSCs had not been clearly identified in bladder UC[13,27,32,35], although their possible existence was feasible since the disease is characterised by frequent recurrences and a high 
risk of progression for some groups of patients[31]. Some high-grade UCs appeared to possess the molecular imprints of stemness, demonstrating a TIC gene expression signature[18] or activity in gene sets that was associated with human embryonic stem cell identity[17,38], or nuclear accumulation of $\beta$ catenin (evidence of Wnt signalling)[18]. Evidence in support of the existence of CSCs in bladder UC could also be found elsewhere in the literature: Oct-3/4 is a transcription factor that is a key regulator of pluripotency and self-renewal in embryonic stem cells and is also expressed in bladder UCs, with intense expression associated with disease progression and metastasis[40]. Some workers also claimed to have isolated CSCs from bladder tumours and bladder cancer cell lines[41,42], and bladder cancer cell populations expressing the putative stem cell marker CD44[27] demonstrate an enhanced ability to form tumours in mice[18].

More recently, other workers also identified the existence of cancer cells showing stem cell features in human bladder UCs[43]. Moreover, different populations of CSCs may reside in the same tumour with diverse tumorigenic potential and distinct genetic anomalies[43]. Therefore, there now appears to be compelling evidence to support the existence of CSCs in bladder UCs, a notion that potentially explains tumour resistance to chemo- and radiotherapy, and disease relapse. Workers are now trying to establish a molecular profile for bladder CSCs to enable their identification within tumour specimens. Preliminary reports appear to suggest that this profile mirrors that seen in the basal and intermediate cells of the normal urothelium; CD44, CD47, and cytokeratins 5 and 17 appear to have a role[7,16,21]. Chan et al. have subsequently identified a gene signature associated with CD44-positive CSCs and also consider CD47 to be a promising target[7]. Our own work and that of others is investigating, in addition, another molecule expressed by basal cells of the normal urothelium and that is also expressed by more aggressive bladder UCs: P-cadherin[33,44,45]. However, it remains unclear whether these various different molecular profiles are inherited from a stem cell-of-origin, or are reactivated during tumour progression[17].

\section{DISCUSSION AND IMPLICATIONS FOR THERAPY}

As discussed above, evidence now seems to support the CSC paradigm for bladder cancer. However, one can also speculate that these events could occur via other molecular mechanisms and pathways, with CSCs being responsible for a minority[13,46], and I thus propose the stepwise process illustrated in Fig. 1. Instead, some workers suggest that tumour heterogeneity arises from genetic and epigenetic differences between tumour cells, resulting from selective pressure during tumorigenesis[18], although the genetic instability operating during the later stages of tumour progression may be so rampant as to outpace this selection with distinct subpopulations generated more rapidly than they can be eliminated[20]. It has also been suggested that UCs arise from more differentiated cells, and self-renewal capacity may be acquired secondarily by inactivation of $p 53$ and $R B 1$ function[13,46]. Equally, the surrounding microenvironment of a UC may play a very significant role[21], possibly even inducing a transitory or reversible CSC-like state[26]: EMT may drive the development of CSCs[20], yet EMT itself is reversible with mesenchymalto-epithelial transition (MET) potentially favouring a cell's colonisation of a distant site, a site that no longer "emits" the EMT-inducing signals that the cell benefited from in the primary tumour[20]. Whether the CSC state reverses in a similar setting and fashion remains unknown, but such tumour-stroma interactions highlight the importance of the tumour microenvironment for all cancer cells, not just $\mathrm{CSCs}$ [20]. Moreover, manipulating the tumour microenvironment may represent an important route to controlling EMT and CSCs[20,21].

The CSC paradigm also needs to be reconciled against the existing proposed models of urothelial carcinogenesis. The traditional "field change", "field cancerization", or "oligoclonal" theory assumes multiple changes in the urothelium resulting from urinary carcinogens, with many transformed cells evolving independently into genetically unrelated tumours in a synchronous, metachronous, and multifocal fashion[47]. However, the identification of the specific multiple and complex chromosomal alterations in bladder TCC has led to the development of the "clonal" theory of bladder cancer pathogenesis, 


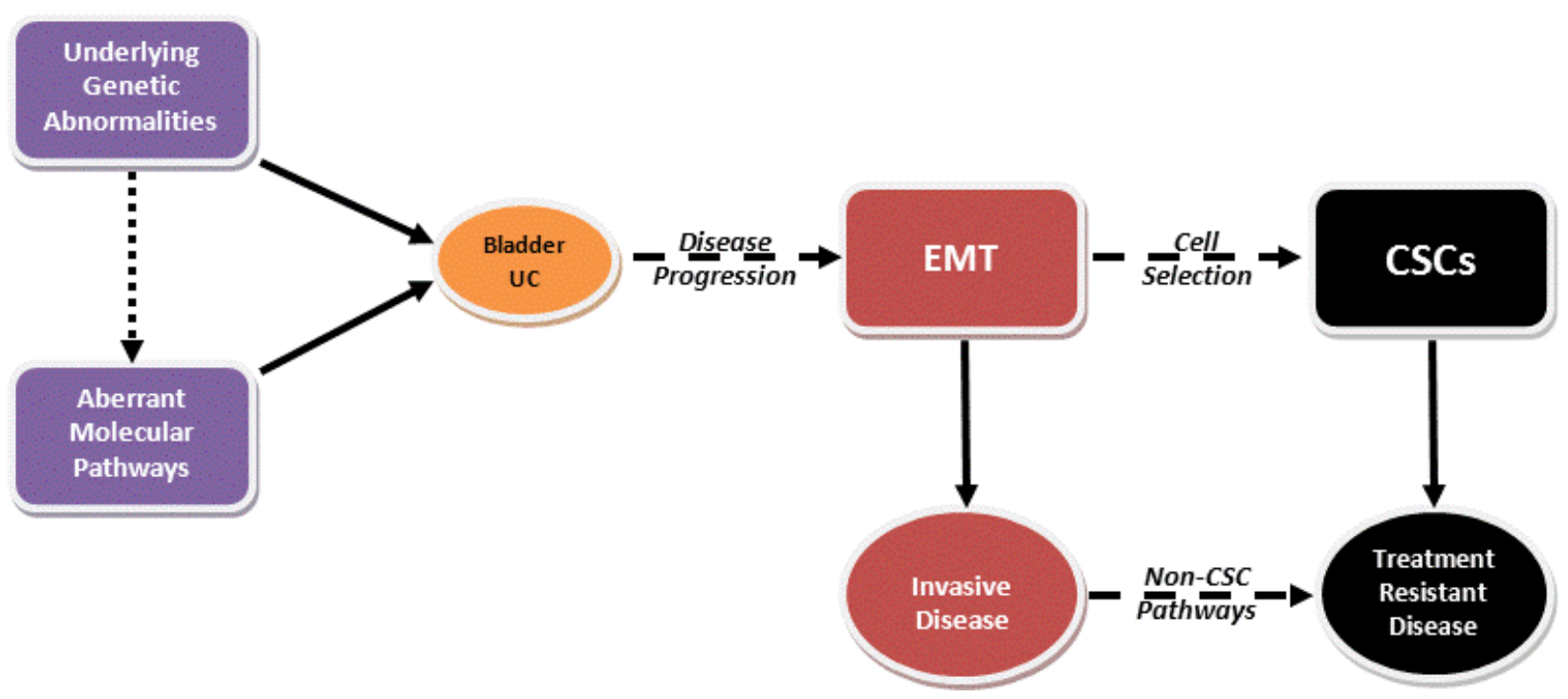

FIGURE 1. A proposed model for the development of bladder UC CSCs.

where it is postulated that multifocal and recurrent tumours evolve from a single transformed cell from which all progeny share several identical genetic mutations[47,48]: a number of early "hits" with subsequent losses of "forerunner genes" results in the selection and vast clonal expansion (by intraepithelial spreading) of mutant cells with a growth advantage; following further "hits", these cells become dysplastic, and may halt their differentiation and acquire a capacity for regenerating tumour growth[27,31,32,49,50]. If we now return to the original three hypotheses:

1. "Cancer cell populations may include CSCs". Bladder cancer cell populations do appear to include CSCs, although their abundance remains unknown.

2. "Tumours may originate from the transformation of normal stem cells[13,19,31,32]". This may be the case in other malignancies, but appears less likely for bladder UCs. As discussed above, some bladder tumours do demonstrate Wnt signalling activity[38], but the majority do not[44,51], and stem-like characteristics are not seen until late in the disease. Clonality appears to dominate in the early stages, with progression resulting in genetic instability, heterogeneity, and EMT. It appears that CSCs may evolve at this stage, and possibly even multiple CSC subpopulations in a model similar to field cancerization with tumour microenvironments across the tumour mass each generating their own distinct CSCs.

3. "Similar signalling pathways may regulate stem cells and cancer cells[13,17,19]". As discussed above, this appears less likely for bladder UC.

From a treatment aspect, it is sensible to consider that the elimination of CSCs will yield more durable therapeutic responses in bladder UC[7,21]. In addition, CSCs may be responsible for tumour dormancy whereby latent tumour cells persist after seemingly successful treatment, only to recur years or decades later and result in life-threatening disease[20]. The next steps for research lie in validating a group of markers that identify bladder CSCs so that their abundance in this setting can be clarified and so that the clinical problem can be more clearly defined. We may then have to consider identifying therapies that are able to specifically target CSCs, since these cells appear to be equipped with a variety of intrinsic properties that enable them to survive treatment with current therapies[21]. Unfortunately, the answers are unlikely to lie with the current so-called "targeted therapies", such as cetuximab, since an epithelial phenotype is required for response by bladder UCs in vitro[52], and loss of the epithelial cell adhesion molecule and tumour suppressor E-cadherin correlates with a poor response[53,54]. Tumour-stroma 
interactions and the tumour microenvironment appear to be of increasing importance in this setting, and identifying the events that accompany MET could be highly significant and lead to specific anti-CSC therapies. Tailored approaches may therefore be required on a patient-by-patient basis to identify the existence of CSCs within a particular tumour, to subsequently identify the different CSC populations, and then to utilise therapies to eradicate CSCs along with non-CSCs within that tumour. Effective and durable treatment may thus have to rely on increasingly complex combinations of different classes of agents. As well as the discovery of new therapeutics, the utilisation of new platforms (e.g., next-generation sequencing) to further characterise tumours alongside existing conventional histopathology may also be required.

\section{CONCLUSIONS}

It is highly relevant to the growing worldwide bladder cancer patient population that we and others continue to investigate the existence, abundance, and molecular pathogenesis of bladder cancer stem cells. In the future, our therapeutic approaches should target the underlying genetic abnormalities seen in bladder cancer, the subsequent aberrant molecular pathways, and the evolution of CSCs to further optimise the management of this significant disease.

\section{REFERENCES}

1. van Rhijn, B.W., Burger, M., Lotan, Y., Solsona, E., Stief, C.G., Sylvester, R.J., et al. (2009) Recurrence and progression of disease in non-muscle-invasive bladder cancer: from epidemiology to treatment strategy. Eur. Urol. 56(3), 430-442.

2. Ploeg, M., Aben, K.K., and Kiemeney, L.A. (2009) The present and future burden of urinary bladder cancer in the world. World J. Urol. 27(3), 289-293.

3. (2009) CancerStats Key Facts - Bladder Cancer. Cancer Research UK.

4. Wallace, D.M., Bryan, R.T., Dunn, J.A., Begum, G., and Bathers, S. (2002) Delay and survival in bladder cancer. BJU Int. 89(9), 868-878.

5. Oosterlinck, W., Lobel, B., Jakse, G., Malmstrom, P.U., Stockle, M., and Sternberg, C. (2002) Guidelines on bladder cancer. Eur. Urol. 41(2), 105-112.

6. Lorusso, V. and Silvestris, N. (2005) Systemic chemotherapy for patients with advanced and metastatic bladder cancer: current status and future directions. Ann. Oncol. 16(Suppl 4), iv85-iv89.

7. Chan, K.S., Volkmer, J.P., and Weissman, I. (2010) Cancer stem cells in bladder cancer: a revisited and evolving concept. Curr. Opin. Urol. 20(5), 393-397.

8. Advanced Bladder Cancer (ABC) Meta-analysis Collaboration (2005) Neoadjuvant chemotherapy in invasive bladder cancer: update of a systematic review and meta-analysis of individual patient data advanced bladder cancer (ABC) meta-analysis collaboration. Eur. Urol. 48(2), 202-205.

9. Castillo-Martin, M., Domingo-Domenech, J., Karni-Schmidt, O., Matos, T., and Cordon-Cardo, C. (2010) Molecular pathways of urothelial development and bladder tumorigenesis. Urol. Oncol. 28(4), 401-408.

10. Cooperberg, M.R., Porter, M.P., and Konety, B.R. (2009) Candidate quality of care indicators for localized bladder cancer. Urol. Oncol. 27(4), 435-442.

11. Donat, S.M., Shabsigh, A., Savage, C., Cronin, A.M., Bochner, B.H., Dalbagni, G., et al. (2009) Potential impact of postoperative early complications on the timing of adjuvant chemotherapy in patients undergoing radical cystectomy: a high-volume tertiary cancer center experience. Eur. Urol. 55(1), 177-185.

12. Kaufman, D.S. (2006) Challenges in the treatment of bladder cancer. Ann. Oncol. 17(Suppl 5), v106-v112.

13. Moltzahn, F.R., Volkmer, J.P., Rottke, D., and Ackermann, R. (2008) "Cancer stem cells"-lessons from Hercules to fight the Hydra. Urol. Oncol. 26(6), 581-589.

14. Shabsigh, A., Korets, R., Vora, K.C., Brook, C.M., Cronin, A.M., Savage, C., et al. (2009) Defining early morbidity of radical cystectomy for patients with bladder cancer using a standardized reporting methodology. Eur. Urol. 55(1), 164-174.

15. Mani, S.A., Guo, W., Liao, M.J., Eaton, E.N., Ayyanan, A., Zhou, A.Y., et al. (2008) The epithelial-mesenchymal transition generates cells with properties of stem cells. Cell 133(4), 704-715.

16. McConkey, D.J., Lee, S., Choi, W., Tran, M., Majewski, T., Lee, S., et al. (2010) Molecular genetics of bladder cancer: emerging mechanisms of tumor initiation and progression. Urol. Oncol. 28(4), 429-440. 
17. Ben-Porath, I., Thomson, M.W., Carey, V.J., Ge, R., Bell, G.W., Regev, A., et al. (2008) An embryonic stem celllike gene expression signature in poorly differentiated aggressive human tumors. Nat. Genet. 40(5), 499-507.

18. Chan, K.S., Espinosa, I., Chao, M., Wong, D., Ailles, L., Diehn, M., et al. (2009) Identification, molecular characterization, clinical prognosis, and therapeutic targeting of human bladder tumor-initiating cells. Proc. Natl. Acad. Sci. U. S. A. 106(33), 14016-14021.

19. Reya, T., Morrison, S.J., Clarke, M.F., and Weissman, I.L. (2001) Stem cells, cancer, and cancer stem cells. Nature 414(6859), 105-111.

20. Hanahan, D. and Weinberg, R.A. (2011) Hallmarks of cancer: the next generation. Cell 144(5), 646-674.

21. Brandt, W.D., Matsui, W., Rosenberg, J.E., He, X., Ling, S., Schaeffer, E.M., et al. (2009) Urothelial carcinoma: stem cells on the edge. Cancer Metastasis Rev. 28(3-4), 291-304. Bryan, R.T., Hussain, S.A., James, N.D., Jankowski, J.A., and Wallace, D.M. (2005) Molecular pathways in bladder cancer: part 2. BJU Int. 95(4), 491-496.

23. Bryan, R.T., Hussain, S.A., James, N.D., Jankowski, J.A., and Wallace, D.M. (2005) Molecular pathways in bladder cancer: part 1. BJU Int. 95(4), 485-490. conditions of the urothelium. Urol. Oncol. 28(4), 409-428.

Rosen, J.M. and Jordan, C.T. (2009) The increasing complexity of the cancer stem cell paradigm. Science 324(5935), 1670-1673.

questions. Nat. Rev. Cancer 8(10), 755-768.

28. Chiang, A.C. and Massague, J. (2008) Molecular basis of metastasis. N. Engl. J. Med. 359(26), $2814-2823$.

29. Gupta, P.B., Chaffer, C.L., and Weinberg, R.A. (2009) Cancer stem cells: mirage or reality? Nat. Med. 15(9), 10101012.

30. Clarke, M.F., Dick, J.E., Dirks, P.B., Eaves, C.J., Jamieson, C.H., Jones, D.L., et al. (2006) Cancer stem cells-perspectives on current status and future directions: AACR Workshop on cancer stem cells. Cancer Res. 66(19), 9339-9344.

31. Hoglund, M. (2007) On the origin of syn- and metachronous urothelial carcinomas. Eur. Urol. 51(5), $1185-1193$.

32. Kurzrock, E.A., Lieu, D.K., Degraffenried, L.A., Chan, C.W., and Isseroff, R.R. (2008) Label-retaining cells of the bladder: candidate urothelial stem cells. Am. J. Physiol. Renal Physiol. 294(6), F1415-F1421.

33. Bryan, R.T. and Tselepis, C. (2010) Cadherin switching and bladder cancer. J. Urol. 184(2), $423-431$.

34. Signoretti, S., Pires, M.M., Lindauer, M., Horner, J.W., Grisanzio, C., Dhar, S., et al. (2005) p63 regulates commitment to the prostate cell lineage. Proc. Natl. Acad. Sci. U. S. A. 102(32), 11355-11360.

35. Nguyen, M.M., Lieu, D.K., Degraffenried, L.A., Isseroff, R.R., and Kurzrock, E.A. (2007) Urothelial progenitor cells: regional differences in the rat bladder. Cell Prolif. 40(2), 157-165.

36. Thangappan, R. and Kurzrock, E.A. (2009) Three clonal types of urothelium with different capacities for replication. Cell Prolif. 42(6), 770-779.

37. Barker, N., van Es, J.H., Kuipers, J., Kujala, P., van den Born, M., Cozijnsen, M., et al. (2007) Identification of stem cells in small intestine and colon by marker gene Lgr5. Nature 449(7165), 1003-1007.

38. He, X., Marchionni, L., Hansel, D.E., Yu, W., Sood, A., Yang, J., et al. (2009) Differentiation of a highly tumorigenic basal cell compartment in urothelial carcinoma. Stem Cells 27(7), 1487-1495.

39. Nusse, R. (2008) Wnt signaling and stem cell control. Cell Res. 18(5), 523-527.

40. Chang, C.C., Shieh, G.S., Wu, P., Lin, C.C., Shiau, A.L., and Wu, C.L. (2008) Oct-3/4 expression reflects tumor progression and regulates motility of bladder cancer cells. Cancer Res. 68(15), 6281-6291.

41. Yang, Y.M. and Chang, J.W. (2008) Bladder cancer initiating cells (BCICs) are among EMA-CD44v6+ subset: novel methods for isolating undetermined cancer stem (initiating) cells. Cancer Invest. 26(7), 725-733.

42. Ning, Z.F., Huang, Y.J., Lin, T.X., Zhou, Y.X., Jiang, C., Xu, K.W., et al. (2009) Subpopulations of stem-like cells in side population cells from the human bladder transitional cell cancer cell line T24. J. Int. Med. Res. 37(3), 621630 .

43. Bentivegna, A., Conconi, D., Panzeri, E., Sala, E., Bovo, G., Vigano, P., et al. (2010) Biological heterogeneity of putative bladder cancer stem-like cell populations from human bladder transitional cell carcinoma samples. Cancer Sci. 101(2), 416-424.

44. $\quad$ Bryan, R.T., Atherfold, P.A., Yeo, Y., Jones, L.J., Harrison, R.F., Wallace, D.M., et al. (2008) Cadherin switching dictates the biology of transitional cell carcinoma of the bladder: ex vivo and in vitro studies. J. Pathol. 215(2), 184194.

45. Van Marck, V., Stove, C., Jacobs, K., Van den Eynden, G., and Bracke, M. (2011) P-cadherin in adhesion and invasion: opposite roles in colon and bladder carcinoma. Int. J. Cancer 128(5), 1031-1044.

46. Bryan, R.T., Zeegers, M.P., James, N.D., Wallace, D.M., and Cheng, K.K. (2009) Biomarkers in bladder cancer. BJU Int. 105(5), 608-613.

47. Garcia, S.B., Park, H.S., Novelli, M., and Wright, N.A. (1999) Field cancerization, clonality, and epithelial stem cells: the spread of mutated clones in epithelial sheets. J. Pathol. 187(1), 61-81. 
48. Sidransky, D., Frost, P., Von Eschenbach, A., Oyasu, R., Preisinger, A.C., and Vogelstein, B. (1992) Clonal origin bladder cancer. N. Engl. J. Med. 326(11), 737-740.

49. Majewski, T., Lee, S., Jeong, J., Yoon, D.S., Kram, A., Kim, M.S., et al. (2008) Understanding the development of human bladder cancer by using a whole-organ genomic mapping strategy. Lab. Invest. 88(7), 694-721.

50. $\quad$ Crawford, J.M. (2008) The origins of bladder cancer. Lab. Invest. 88(7), 686-693.

51. Stoehr, R., Krieg, R.C., Knuechel, R., Hofstaedter, F., Pilarsky, C., Zaak, D., et al. (2002) No evidence for involvement of beta-catenin and APC in urothelial carcinomas. Int. J. Oncol. 20(5), 905-911.

52. Adam, L., Zhong, M., Choi, W., Qi, W., Nicoloso, M., Arora, A., et al. (2009) miR-200 expression regulates epithelial-to-mesenchymal transition in bladder cancer cells and reverses resistance to epidermal growth factor receptor therapy. Clin. Cancer Res. 15(16), 5060-5072.

53. Black, P.C. and Dinney, C.P. (2007) Bladder cancer angiogenesis and metastasis--translation from murine model to clinical trial. Cancer Metastasis Rev. 26(3-4), 623-634.

54. Black, P.C., Brown, G.A., Inamoto, T., Shrader, M., Arora, A., Siefker-Radtke, A.O., et al. (2008) Sensitivity to epidermal growth factor receptor inhibitor requires E-cadherin expression in urothelial carcinoma cells. Clin. Cancer Res. 14(5), 1478-1486.

This article should be cited as follows:

Bryan, R.T. (2011) Bladder cancer and cancer stem cells: basic science and implications for therapy. TheScientificWorldJOURNAL: TSW Urology 11, 1187-1194. DOI 10.1100/tsw.2011.117. 


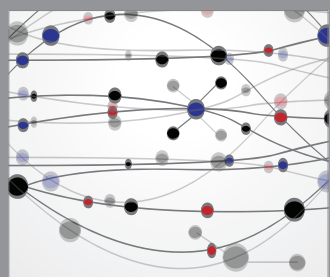

The Scientific World Journal
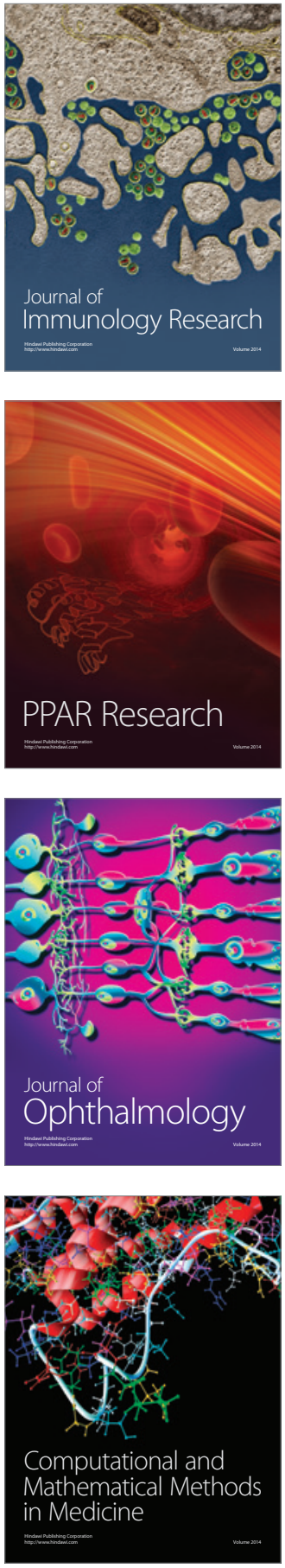

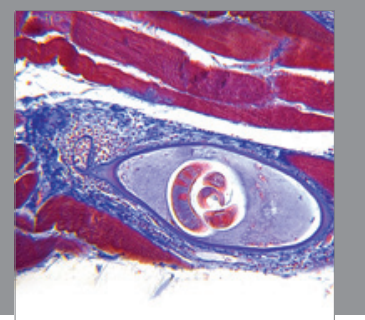

Gastroenterology

Research and Practice
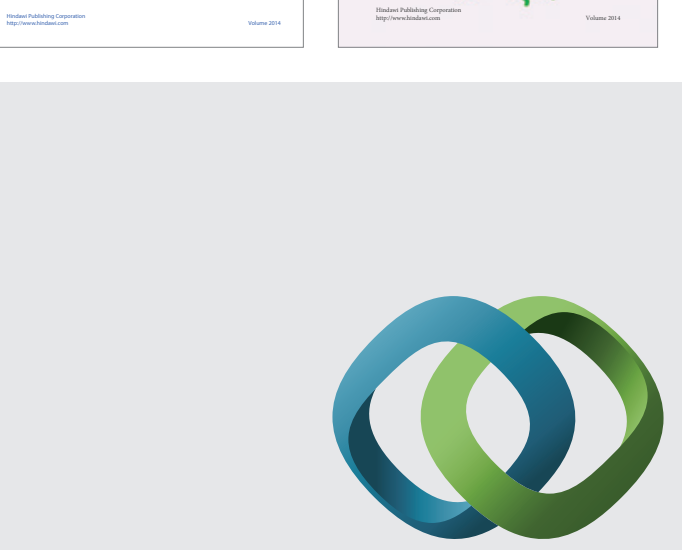

\section{Hindawi}

Submit your manuscripts at

http://www.hindawi.com
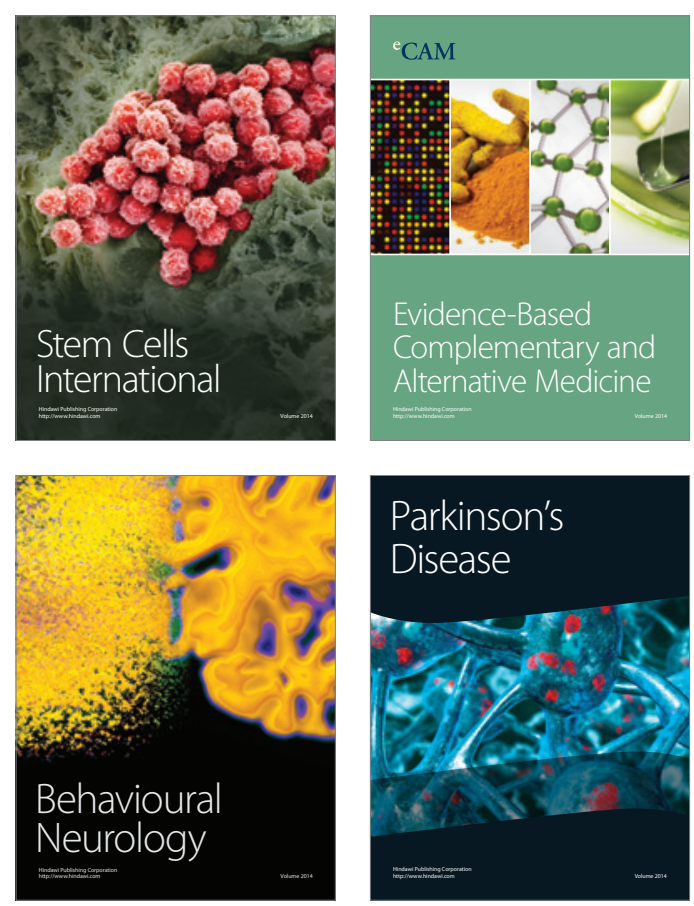

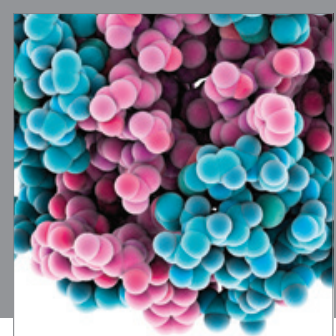

Journal of
Diabetes Research

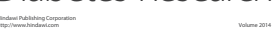

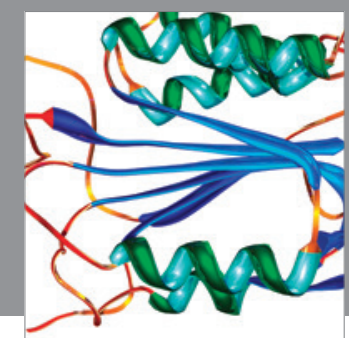

Disease Markers
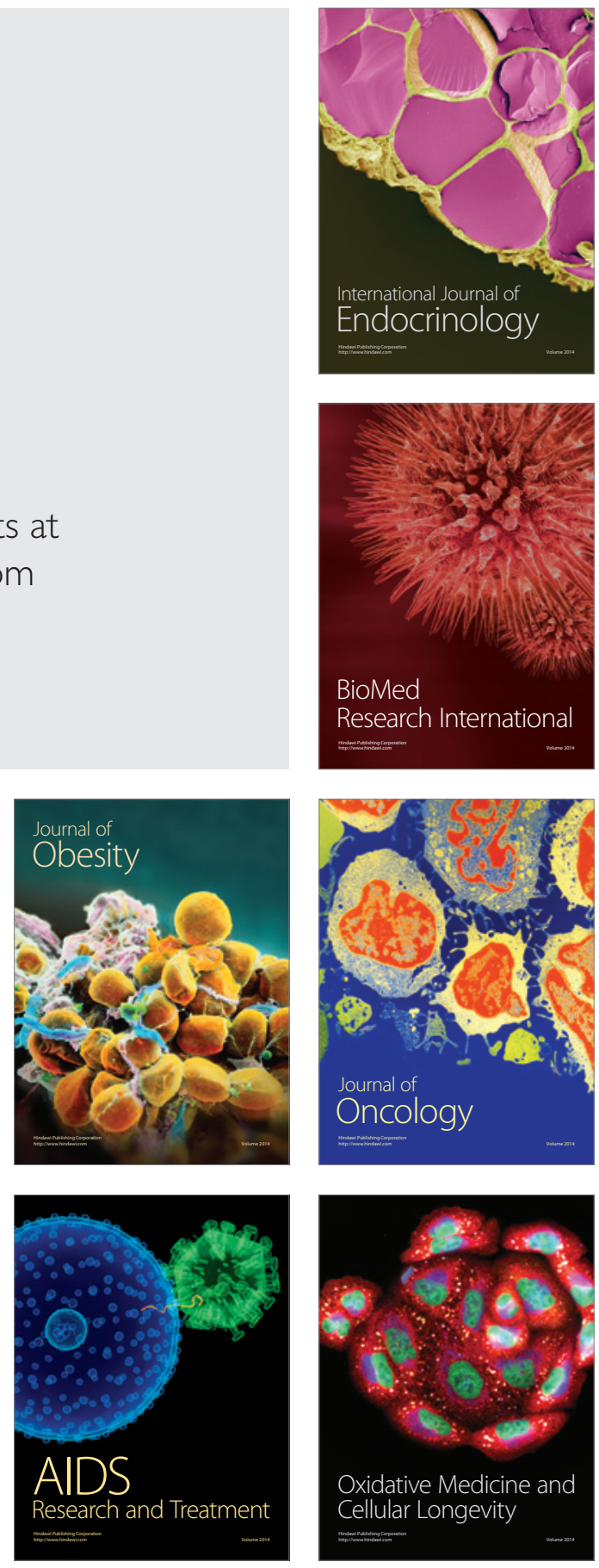